\title{
Exercício democrático: a tecnologia e o surgimento de um novo sujeito
}

\section{Democratic exercise: technology and the emergence of a new subject}

\author{
Danielle Anne Pamplona* \\ Cinthia Obladen de Almendra Freitas*
}

\section{Resumo}

O texto procura justificar a adoção do modelo de democracia representativa como o mais próximo de possível implementação nos dias atuais. O modelo adotado é o de Carlos Santiago Nino, para quem a democracia é um processo de discussão moral que está sempre conformado por um determinado período de tempo. Todavia, alertando para as dificuldades inerentes ao exercício democrático em qualquer modelo escolhido, aponta para a possível saída de utilização da tecnologia para aproximar o modelo ideal da realidade. Assim, reconhecendo que os instrumentos tecnológicos já são utilizados como meio de comunicação e agregação de membros da comunidade, propõe sua intensificação. A intenção de sugerir a intensificação do uso dos instrumentos tecnológicos serve ao incremento das possibilidades de participação democrática. Reconhece, com base nos autores estudados, o surgimento de um novo sujeito político-tecno-social e explora o exemplo brasileiro do sítio chamado "e-democracia", criado pelo Legislativo brasileiro. Nesse sítio, há a real possibilidade de cada cidadão brasileiro manifestar-se, de diferentes modos, acerca da agenda do Poder Legislativo.

Palavras-chave: Democracia. Sociedade. Redes Sociais.

* Professora titular da PUCPR. Professora permanente do Programa de Pós-Graduação em Direito (PPGD) da mesma instituição. Doutora em Direito pela UFPR - Universidade Federal do Paraná. Curitiba - PR - Brasil. E-mail: danielle.pamplona@pucpr.br

** Professora titular da PUCPR. Professora Permanente dos Programas de Pós-Graduação em Direito (PPGD) e em Informática (PPGla) da mesma instituição. Doutora em Informática pela PUCPR. Curitiba - PR - Brasil. E-mail: cinthia@ppgia.pucpr.br 


\section{Abstract}

The text seeks to justify the adoption of the representative democracy model as the closest one from possible implementation today. The model adopted is the one presented by Carlos Santiago Nino, for whom democracy is a process of moral argument always conformed by a certain period of time. The text was about the inherent difficulties in the democratic exercise in any chosen model, although it points to the possible solution of using technology to approximate the ideal model to reality. Thus, recognizing that technological tools are already used as means of communication and aggregation of community members, proposes its intensification. The intention to suggest the increased use of technological tools serves to multiply the opportunities for democratic participation. It recognizes, based on the authors studied, the emergence of a new techno-social-political subject and explores the example of the Brazilian site called e-democracy, created by the Brazilian legislative branch. On this site, there is the real possibility of every Brazilian citizen to manifest itself in different ways about the Legislature 's agenda.

Keywords: Democracy. Society. Social Networks.

\section{Introdução}

Há muito tempo a doutrina se debate sobre o tema da democracia, entre outras razões, a fim de tentar desvendar os melhores instrumentos para tornar seu exercício mais próximo de seu ideal. A própria questão acerca de qual seja o modelo ideal já permite uma longa discussão, conteúdo para muito mais páginas do que este artigo contém. Há autores que só veem processo democrático quando se aceitam preferências divergentes que surgem da necessidade de outras pessoas; para outros, o processo democrático serve para e é o responsável por ajustar as preferências pessoais para criar uma moral que abranja determinados valores. Sem entrar na discussão acerca das virtudes da adoção de um regime democrático, o presente artigo, partindo das características da democracia ateniense, vislumbra a proposta da Carlos Santiago Nino sobre democracia deliberativa, indicando instrumentos atuais e palpáveis para sua concretização. O trabalho, fruto de estudos e discussões 
em grupo de pesquisa, inclui uma visão a partir da tecnologia, mais especificamente por meio das redes sociais. Estruturas estas que vêm permitindo a formação de um novo sujeito, denominado político-tecnosocial. Para Castells (1999, p. 25):

É claro que a tecnologia não determina a sociedade. Nem a sociedade escreve o curso da transformação tecnológica, uma vez que muitos fatores, inclusive criatividade e iniciativa empreendedora, intervêm no processo de descoberta científica, inovação tecnológica e aplicações sociais, de forma que o resultado final depende de um complexo padrão interativo. [...] a tecnologia é a sociedade, e a sociedade não pode ser entendida ou representada sem suas ferramentas tecnológicas.

É justamente sobre o entendimento desse novo sujeito, que explora a democracia de modo socialmente compartilhado por meio do uso das novas tecnologias de informação e comunicação (TIC), que o artigo se reveste de novidade, abordando tais elementos sob a ótica do exercício democrático no Brasil.

\section{Exercícios de democracia}

O exercício da democracia é um tema recorrente em estudos de algumas áreas do conhecimento. Sob vários prismas, é possível realizar diferentes análises, seja partindo de estudos descritivos de realidades selecionadas, seja partindo de estudos propositivos. 0 frequente retorno ao tema evidencia sua incompletude, evidencia que ainda se está por realizar uma democracia que satisfaça aos anseios de igualdade de tratamento e condições das pessoas. Analisar a extensão do exercício democrático de uma sociedade traz inúmeras indagações acerca do modo de estruturação das instituições e de interação entre as mesmas, o modo de organização e operação dos diversos atores assim como acerca de suas relações com as instituições. Aqui, tomase o termo democracia pela conceituação de Nino (2007, p. 187), para quem é "la única forma política que reconoce la autonomía y dignidad 
moral de los ciudadanos al atribuirles en conjunto la responsabilidad por la construcción del marco social en el que se desarrollarán sus propios planes de vida"1.

Há muitos bons estudos acerca das diferentes democracias instaladas em países ocidentais. Todos remetem a Adam Przerworski, em livro publicado pela Cambridge University, em 1995 (PRZERWORSKI, 1995). Ele não somente identificou as características dos regimes democráticos que estudou, como também se preocupou em estabelecer quais as condições que mantiveram esses regimes instalados por mais tempo e de modo mais enraizado. O foco, no presente artigo, é partir da descrição do que era a democracia ateniense para dela retirar uma das características ideais da democracia e tentar demonstrar que esse ideal nunca esteve tão perto de ser alcançado.

Deve-se enfrentar uma provável objeção inicial. A escolha da democracia ateniense deve ser justificada. Ocorre que o exemplo ateniense tem servido de modelo de comparação ou, no mínimo, de ponto inicial da discussão sobre as possibilidades de realização da democracia hoje. Parte-se da experiência ateniense porque ela permite identificar o que se constituiu em um governo para e pelo povo. Assim, ao perceber não só os pontos positivos da ideia de democracia ali instituída, mas também ao perceber suas limitações no exercício diário, pode-se chegar a conclusões úteis ao objetivo deste artigo.

A democracia clássica é um modelo de impossível realização na atualidade, mas, por suas virtudes, como mencionado anteriormente, entende-se útil uma breve incursão a fim de se retirar dela o que seja passível de utilização para o modelo que aqui é apresentado.

A democracia exercida em Atenas servia a um território bastante diminuto, com uma população pequena e sem muita heterogeneidade. Esse modelo era exercido essencialmente no seio das cidades-estado,

Tradução livre: '...é a única forma política que reconhece a autonomia e dignidade moral dos cidadãos ao atribuir-Ihes em conjunto a responsabilidade pela construção do marco social em que se desenvolvem seus próprios planos de vida." 
não se falando de democracia entre as cidades-estado, já que elas constituíam entidades autônomas que admitiam alianças somente de forma excepcional, como em caso de necessidades militares. Por outro lado, várias estimativas atribuem à Atenas a população de, no máximo, quarenta mil habitantes. Entre estes, a parcela considerada como detentora da cidadania era ainda menor. O exercício da cidadania era honra concedida somente aos homens maiores de vinte anos, filhos de atenienses, excluindo-se do rol mulheres, crianças e outros homens, inclusive os metecos, responsáveis pela prosperidade econômica da cidade-estado. Esse rol diminuto de cidadãos era sopesado pelo fato de que, uma vez cidadão, as obrigações eram muitas. O exercício da isonomia (igualdade) e da isegoria (igualdade de condições de manifestação) só era concedido se o cidadão tivesse participado das discussões acerca de determinado assunto. A participação cidadã era uma tarefa penosa, que exigia muito tempo dos cidadãos atenienses, mas ao contrário do que se poderia concluir em uma primeira análise, ela não era vista como um peso, como um fardo. Ao contrário, era encarada como afirmação da autonomia de cada indivíduo. Vilani (2000, p. 19) afirma:

Dentre as instituições da Grécia Antiga destacou-se, pelo seu significado político, a cidade-república de Atenas - a pólis -, que teve seu apogeu entre os séculos VI e IV a.C. Ali, os cidadãos, em assembleia, reuniam-se para discutir e deliberar sobre as leis e a organização da vida coletiva. O demos era soberano e tinha a autoridade suprema para exercer as funções legislativa e judiciaria. Os requisitos para pertencer ao espaço pólis eram a liberdade e a igualdade. Para o ateniense, o homem só podia exercer a política em liberdade e só podia ser livre entre os seus pares.

A autonomia do homem ateniense com mais de vinte anos de idade era afirmada em cada oportunidade que se lhe dava para que participasse das decisões tomadas no âmbito público. Os cargos públicos eram preenchidos por sorteio ou eleição, para mandatos curtos - de até mesmo um dia - e eram preenchidos por indivíduos pagos para tanto, sem o deferimento de qualquer regalia que o tornasse diferente 
dos outros cidadãos. O exercício dessa democracia era possível porque, dentre outros requisitos, a extensão territorial era pequena e os indivíduos dispunham de tempo para se dedicar aos assuntos públicos ${ }^{2}$.

Essas características são fonte dos maiores problemas enfrentados hoje para a realização democrática. De fato, os indivíduos não têm tempo disponível e as extensões territoriais envolvem uma grande diversidade de indivíduos, os quais, apesar da existência de inúmeras possibilidades e meios de comunicação (internet, celular, computador, telefone, TV, rádio, jornal, entre outros), não optam por exercer a democracia. Nesse ponto, entende-se como primordial dois fatores: habilidade para uso de computadores e internet e falta de interesse.

De acordo com o levantamento realizado pelo Centro de Estudos sobre as Tecnologias da Informação e da Comunicação (CETIC.br), entre 2005 e 2009, os principais fatores inibidores para o uso da internet estão associados ao seguintes motivos (CETIC.br, 2010, p. 82-83):

- 53\% com a "falta de habilidade" com o computador ou com a internet;

- $36 \%$ com a "falta de interesse";

- $20 \%$ com a "falta de condições para pagar o acesso"; e

- $21 \%$ com a "falta de local para o acesso".

O CETIC.br explica que "a falta de habilidade é a principal barreira para o acesso à Internet em todas as classes sociais, com uma maior proporção nas classes D e E”. Complementa ainda que ao se analisar a categoria "grau de instrução", o motivo "falta de habilidade" é declarado preponderantemente por analfabetos ou pelos que só têm educação infantil. O relatório pondera de forma direta que "o cidadão brasileiro ainda não está 'educado' ou não teve acesso a treinamentos gratuitos específicos para o uso eficiente dos espaços virtuais, entretanto essa habilidade é determinante para tornar viável o uso do computador e da

2 O que só era possível porque a sociedade ateniense se baseava em um regime escravagista. Tudo era feito para o cidadão e a ele restava tão somente a obrigação de participar das decisões políticas. 
Internet e é pressuposto para uma real inclusão digital no país" (CETIC. br, 2010, p. 83).

É importante observar que o relatório mostra que, em 2005, apenas $17 \%$ dos domicílios brasileiros em área urbana possuíam um computador. Tal percentual cresceu em 2009 para $36 \%$. Já ao se analisar o uso da internet, o salto, no mesmo período, foi de $13 \%$ para $27 \%$. Em números absolutos, mais de 18 milhões de lares brasileiros possuem um computador para uso familiar e, desse total, 13,5 milhões acessam a internet (CETIC.br, 2010). Aponta-se também que, ao se levar em consideração o Brasil (área urbana e rural) em 2009, quando os dados foram levantados, $39 \%$ da população brasileira com mais de 10 anos de idade já era usuária de internet, ou seja, 63,9 milhões de brasileiros (CETIC.br, 2010).

Ao se observar dados informados pelo lbope $^{3}$, para o $2^{\circ}$. trimestre de 2013, tem-se o registro de 105 milhões de brasileiros conectados à internet, considerando-se qualquer ambiente, ou seja, domicílio, trabalho, lan houses, escolas, locais públicos e outras localidades. 0 Ibope informa também que em relação aos "dois últimos anos, o número de pessoas com acesso à internet em casa passou de 57,9 milhões, em 2011, para 76,6 milhões, em 2013", registrando aumento de $32 \%$.

Observa-se, portanto, que a situação de acesso vem mudando progressivamente, mas ainda necessita-se "olhar" para aqueles que ou não têm condições de pagar o acesso (20\%) ou não possuem as habilidades necessárias para fazê-lo (53\%) (CETIC.br, 2010). Com relação à existência de parcela significativa com "falta de interesse" (36\%), o relatório da empresa Pew Internet (HORRIGAN, 2009) apresenta 10 categorias de usuários, estabelecidos entre 3.553 entrevistados americanos. Infelizmente, não se pode encontrar relatório categorizando os usuários brasileiros, mas apresenta-se a seguir um

Disponível em <http://www.ibope.com.br/pt-br/noticias/paginas/numero-de-pessoas-com-acessoa-internet-passa-de-100-milhoes.aspx> Acesso em 20 de jan. de 2014 . 
conjunto de considerações relevantes ao entendimento da "falta de interesse" das pessoas em utilizar os meios tecnológicos.

Assim, de acordo com o relatório, duas categorias chamam atenção (HORRIGAN, 2009):

- $10 \%$ compreendem a categoria dos —indiferentes à tecnologia e

- $14 \%$ compreendem a categoria dos — fora da rede.

O relatório entende como indiferentes à tecnologia aqueles que "são, como grupo, mais velhos do que os outros usuários e parecem ter estabelecido padrões de obter informações ou se manterem em contato com amigos e familiares que não contam com a tecnologia moderna" (FREITAS, 2012, p. 64). Por outro lado, os categorizados como sendo fora da rede, "são as pessoas que não têm acesso on-line ou um telefone celular, porém, alguns podem ter tido experiência com estas tecnologias" (FREITAS, 2012, p. 64).

Além disso, o relatório levanta outras possibilidades para o grupo "fora da rede", ou seja, "talvez o computador tenha deixado de funcionar e a pessoa não saiba o que fazer para consertá-lo, talvez o plano de telefone celular tenha se tornado muito caro ou a pessoa tenha usado tão pouco os serviços que tenha decidido cancelá-los" (HORRIGAN, 2009, p. 14). Para Freitas (2012, p. 64), é "interessante o relatório não apontar uma categoria de não usuários, ou seja, que realmente desconhece o assunto". Continua, ponderando que "esta categoria possui alguns pontos em comum com os brasileiros que não têm acesso à internet".

Dentre todas essas possibilidades de classificação dos indivíduos, salta aos olhos aqueles que não demonstram interesse pelo uso do instrumento da internet. Todo esse agrupamento de pessoas, que por um motivo ou outro deixa de utilizar as ferramentas disponíveis na internet, compõe um grande grupo que é reconhecido pela característicia de não se interessar pelas atividades próprias de cidadão. Há muito se percebeu que o exercício democrático naqueles moldes atenienses não seria plausível. Com a formatação dos Estados-Nação, houve o reconhecimento de que dentro de determinado território a população seria encarada como um todo, destinatária de igual tratamento. Ora, 
isso demandou o arranjo de novas formas de discussão e tomada de decisões políticas. Deixou de ser possível a manutenção de cidadãos, nos moldes atenienses, também pela premência econômica. Surge a possibilidade de que os indivíduos, em vez de incorporarem o papel de cidadão ativo, possam ser representados. A representação política não deixa de ser um novo arranjo que possibilitou atender as necessidades das novas relações sociais e institucionais. O povo continuaria tomando as decisões, todavia, por meio de seus representantes, escolhidos pelo próprio povo para dizer qual seria sua vontade diante de diversos temas. O arranjo democrático surgido aí é conhecido como democracia

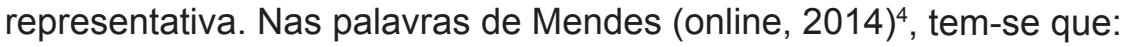

Representation is a pragmatic device to circum vent the practical difficulties of adopting the original democratic standard. In modern societies, given their magnitude and complexity, individuals cannot be up for politics all the time. The size of the demos and the geographical extent of national states, moreover, turn a direct assembly of the People unfeasible. Their participation can only be limited and periodical.

São evidentes, portanto, as dificuldades para a implantação de um exercício democrático nos moldes em que ele surgiu em Atenas.

\section{Democracia deliberativa}

Considerando-se o exposto, o presente artigo apega-se a uma versão de democracia, a deliberativa, nos moldes preconizados por

\footnotetext{
$4 \quad$ Is it all about the last word? Deliberative separation of powers I, p. 33. Tradução livre da autora: 'Representação é um dispositivo pragmático para driblar as dificuldades práticas de adotar o padrão democrático original. Em sociedades modernas, dado às suas magnitude e complexidade, os indivíduos não podem estar à disposição da política todo o tempo. O tamanho do demos e, ainda mais, a extensão geográfica dos estados nacionais, tornam uma Assembleia direta do Povo implausível. A participação do povo só pode ser limitada e periódica". Disponível em <http:// www.researchgate.net/publication/228127867_Is_it_All_About_the_Last_Word_Deliberative_ Separation_of_Powers_1>Acesso em: 10 de jan. 2014.
} 
Carlos Santiago Nino, na tentativa de buscar mecanismos de aplicação plausível no atual cenário brasileiro.

Nino (2007, p. 167) define democracia como "un proceso de discusión moral sujeto a un límite de tiempo". Para tanto, esclarece que diante de determinado impasse, o grupo de pessoas pode tentar, em um primeiro momento, encontrar a solução de modo unânime, todavia, a pressão do tempo fará com que abandonem tal necessidade para passar à votação, a fim de encontrar uma solução, ou seja, o ideal da unanimidade é abandonado pela necessidade de que decisões sejam tomadas em um determinado espaço de tempo.

Assim, a democracia no formato defendido por Nino encontra fundamento na necessidade de reconhecimento do papel individual no processo de tomada de decisões, sem se olvidar de que trata-se, em verdade, de um processo, e como tal, sucede-se ao longo do tempo em idas e vindas de opiniões entre os indivíduos participantes. $\mathrm{O}$ autor não recusa a importância das reflexões individuais nos moldes postos por John Rawls (1999), mas, ao mesmo tempo, lança mão de Jürgen Habermas (1997) para alertar para a relevância do debate coletivo como forma de alcançar os valores morais. Nino faz, em verdade, uma acomodação entre as duas visões, ao menos neste ponto, antagônicas, para retirar do debate coletivo o quanto necessário para satisfazer a maior parcela de indivíduos possível, e da reflexão individual, uma forma válida para encontrar os valores morais. Nas suas palavras (NINO 1999, p. 201):

A diferencia de Habermas, no concibo al consenso, ni siquiera cuando es alcanzado bajo condiciones ideales, como constitutivo de soluciones justas. Tampoco creo que la empresa colectiva de la discusión sea la única forma de conocer esas decisiones justas. Mi posición solo intenta sostener que la democracia deliberativa es método más confiable para lograrlo.

Entende o autor que a democracia deve aliar instrumentos conhecidos de sua fórmula direta com a representação. Sua visão de 
democracia é deliberativa, no sentido de que busca dar aos indivíduos empoderamento para participação. Para ele, todos os indivíduos potencialmente afetados por uma decisão devem ter a oportunidade de participar do processo de tomada de decisões.

Paratentar, pragmaticamente, resolveroimpassedaimpossibilidade de participação de um número maior de cidadãos faz-se necessário um novo olhar sobre os mecanismos à disposição dos indivíduos. 0 tipo democrático que exige a concordância com o importante papel individual, sem olvidar a responsabilidade do conjunto, é denominado de deliberativo. Como o próprio nome indica, a democracia deliberativa demanda a participação popular. Com essa noção de democracia deliberativa em mente, acredita-se que a democracia se constrói a cada momento e é intimamente dependente dos indivíduos que se dispõem a colaborar. No estágio atual de desenvolvimento das sociedades tocadas pelo mundo moderno, é impraticável o modus operandi ateniense: há um número muito maior de envolvidos, com atribuições múltiplas para sua sobrevivência e espalhados em extensões territoriais bastante elastecidas para os modelos gregos.

O nó górdio da questão é, exatamente, como facilitar a participação a ponto de incentivar a manifestação de pessoas que têm o seu tempo ocupado com atividades profissionais, pessoais, familiares, entre outras, que acabam por ocupar todo ou grande parte de seu tempo e lhes exigir energia mental e física que lhes demovem de qualquer participação cidadã.

O que se quer demonstrar no presente artigo é que há alternativa de modelo democrático e faz-se necessário discutir sobre as opções tecnológicas disponíveis para sua implementação.

\section{A tecnologia como meio para o exercício da democracia}

A resposta vem da sociedade de informação por meio das mídias sociais. Sociedade esta que está conectada via rede mundial de computadores, a internet, permitindo a troca de informações 
em qualquer ponto do planeta Terra. É uma sociedade que prima pela velocidade, acessibilidade, disponibilidade e mobilidade, visto que foi atingido, por tal sociedade, um estágio de desenvolvimento caracterizado pela capacidade de obter e compartilhar qualquer informação instantaneamente. Neste contexto, o artigo apresenta o paradigma atual denominado de everyware e segue a discussão analisando o caso brasileiro do sítio "e-democracia". Na sequência, discute a formação de um novo sujeito que se apresenta político, tem acesso às novas tecnologias de informação e comunicação (TIC) e ainda atua politicamente por meio das redes sociais, estabelecendo uma relação entre três elementos básicos, quais sejam: a política, a tecnologia e as redes sociais.

\subsection{O paradigma atual: everyware}

A informação está acessível a partir de qualquer lugar e vive-se um cenário no qual não se está atento a tudo isso o todo o tempo. Vivese a realidade prevista por Weiser (1991), sob a ótica da computação ubíqua, possibilitada pelo desenvolvimento da computação móvel, com a aplicação de sistemas embarcados, e pela computação pervasiva, a qual é entendida pela capacidade dos meios de computação estar distribuídos, de forma imperceptível, nos diferentes ambientes em que se encontram os usuários (MOUTINHO, 2010). Greenfield (2006, p. 9) define um novo e único paradigma, denominado everyware, a saber:

Ever more pervasive, ever harder to perceive, computing has leapt off desktop and insinuated itself into everyday life. Such ubiquitous information technology - "everyware" - will appear in many different contexts and take a wide variety of forms, but it will affect almost every one of us, whether we're aware of it or not. ${ }^{5}$

Tradução livre das autoras: "Ainda mais invasivo, mas difícil de perceber, é que o computador saiu da mesa de trabalho e se insinua em nossa vida diária. Essa tecnologia da informação ubíqua - 'everyware' - aparecerá em muitos contextos diferentes e tomará uma variedade de formas, mas afetará quase todos nós, estejamos ou não conscientes disto." 
Não há mais que se falar somente em hardware e software, muito menos em estruturas do tipo fixo, como telefone fixo ou computador desktop, que significa literalmente "em cima da mesa", ou seja, fixo a um único local e utilizando infraestrutura de fios, cabos e tomadas elétricas.

A computação sem computadores, tal qual prevista por Weiser (1991), trabalha não somente com o conceito de estar em qualquer lugar mas sim em qualquer coisa. Entenda-se "coisa" como sendo qualquer aparato ou equipamento que possa realizar processamento de informações, sejam estes aparentemente eletrônicos ou não.

Para Greenfield (2006), o everyware precisa de um conjunto novo de modos de interface com o ser humano. Isso significa que a interação tangível, gestual e audiovisual cada vez mais estará presente nos mais variados e numerosos lugares do mundo quando comparados aos métodos convencionais (monitor, teclado, mouse).

Outro aspecto interessante do everyware é a descentralização (GREENFIELD, 2006). É preciso perceber que a maioria das pessoas nesse novo paradigma se comporta como usuário ou consumidor da tecnologia de informação $(\mathrm{TI})$, mas uma tendência centrífuga permitirá expandir e gerar interesse de maneira descentralizada nos sistemas (GREENFIELD, 2006).

Deve-se ter em mente também que o everyware é relativo (GREENFIELD, 2006), ou seja, cada resultado ou resposta obtida em um determinado momento depende não somente das ações e atitudes passadas, mas também de um grande número arbitrário de outras entradas (inputs) a partir de pontos distantes e conectados não necessariamente de modo direto (peer-to-peer) por interesse mútuo. Na verdade, o grau de pervasividade e entrelaçamento com o dia a dia das pessoas fará com que cada um reavalie seus relacionamentos com outras pessoas e consigo mesmo (GREENFIELD, 2006).

Nesse contexto, entende-se que as redes sociais personificam um entre muitos exemplos de everyware, visto que elas vêm gerando transformações sociais e políticas (MORAES, 2011; GUARESCHI, 2007; SILVA, 2008). Mas o que se pretende aqui não é tratar especificamente 
sobre as redes sociais, mas sobre as mudanças relacionadas à política e à sociedade a partir delas.

Cabe, portanto, conceituar redes sociais. Para Marteleto (2001, p. 72), as redes sociais são "um conjunto de participantes autônomos, unindo idéias e recursos em torno de valores e interesses compartilhados". Castells (1999, p. 498) considera as redes "um conjunto de nós interconectados. Nó é o ponto no qual uma curva se entrecorta. Concretamente, o que um nó é depende do tipo de redes concretas de que falamos". Uma definição matemática e algorítimica para as redes é apresentada em Freitas (2012, p. 45-47): "as pessoas entram nas redes e relacionam-se. Que não existem ilhas, ou seja, pessoas completamente isoladas da sociedade no sentido mais amplo. E, ainda, que cada nó requer um único link para estar conectado". Não cabe a este artigo discutir os aspectos ilícitos das redes (por exemplo, darknets), mas atentar para tal problema é uma urgência da sociedade tecnológica e democraticamente organizada.

A ideia de que a sociedade pode se aliar à tecnologia para facilitar suas reivindicações e buscar soluções para os problemas que enfrenta não é das autoras deste artigo. De fato, basta observar diferentes manifestações ocorridas em diferentes locais ao longo do ano de 2013. A sucessão de eventos ocorridos no Egito, na Tunísia, na Espanha, na Turquia e, também no Brasil, tendo sido denominado por aqui como "Outono Brasileiro", mostrou que além das redes sociais não havia outra estrutura, ao menos na sociedade brasileira, organizando as manifestações. A sociedade se organizou por meio das redes sociais e elas desempenharam um papel forte e determinante nas ações e pensamentos.

No Brasil, foram contabilizadas 353 cidades envolvidas com as manifestações, tendo sido considerada uma "epidemia" pelo Jornal O Estadão6 ${ }^{6}$. Esse número advém de levantamento realizado em eventos

6 Disponível em: <<http://www.estadao.com.br/noticias/nacional,epidemia-de-manifestacoes-temquase-1-protesto-por-hora-e-atinge-353-cidades,1048461,0.htm>. Acesso em: 20 de out. de 2014. 
no Facebook e em menções da imprensa local. Ainda de acordo com O Estadão, "ao todo, houve pelo menos 490 protestos em três semanas (mais de 22 por dia)".

A sociedade seguiu um novo modelo de organização. O Twitter e o Facebook foram utilizados intensamente para articular os protestos, divulgando hora e local. A etiqueta \#VEMpraRUA mobilizou a população jovem, ou seja, os "nascidos" na sociedade tecnológica (PRENSKY, 2001).

O Brasil ficou perplexo, mas na verdade quem ficou perplexo foram os "migrados", não os "nascidos" (PRENSKY, 2001). Para Prensky (2001), os migrados são as pessoas que se esforçam para ingressar na sociedade tecnológica e que nunca falaram a linguagem digital "sem sotaque". Já os nascidos navegam sem problemas pelo ambiente digital, manipulam equipamentos sem precisar ler o manual do usuário e fazem da estrutura da rede um caminho para tudo o que precisam saber, realizar e executar.

Castells (2007, p. 167) afirma que "as sociedades mudam através do conflito e gerem-se através da política". As manifestações ocorridas no Brasil e no mundo somente confirmam tal afirmação. Além disto, o autor complementa que a internet cada vez mais será uma ferramenta para "actuar, informar, recriar, organizar, dominar e contradominar". Ele explica que "como os movimentos encontraram um meio de organização apropriado, foram-se desenvolvendo a abriram novas vias para a mudança social que, por sua vez, potenciaram o papel da Internet como o seu meio favorito". E esse favoritismo está relacionado com três razões, a saber:

- a mobilização ocorre em torno de valores culturais, ou seja, busca-se a mudança dos códigos de significado nas instituições e, também, na atividade social;

- busca-se preencher o vazio existente pela crise das organizações verticalmente integradas, sendo os partidos políticos esvaziados,

\footnotetext{
${ }^{7}$ \# - significa hashtag, o qual facilita a busca por assuntos de interesse no Twitter, Instagram e Facebook.
} 
os sindicatos reformulados e as associações de cidadãos decadentes;

- ocorre a globalização dos movimentos sociais, ignorando-se as instituições dos Estados-Nação.

Desse modo, compartilha-se da ideia de Castells (2007, p. 186): "Esperava-se que a Internet pudesse ser um instrumento ideal para fomentar a democaria", e, como o próprio autor complementa, "ainda pode sê-lo".

\subsection{O caso brasileiro: e-democracia}

Há algumas estruturas que surgem na internet por movimentação das próprias instituições. Um exemplo é o portal denominado de "e-democracia" (www.edemocracia.camara.gov.br), criado pela Câmara dos Deputados e em utilização desde 2009. A intenção é fomentar a participação dos indivíduos nos debates ocorridos na Câmara. Qualquer cidadão pode se cadastrar e se utilizar do portal para iniciar uma discussão, postar seu ponto de vista, ser mediador de um debate, atividades normalmente conexas com o conteúdo de um projeto de lei que está ali tramitando. Os debates que ali ocorrem são acompanhados pelos deputados federais, tendo, portanto, potencial transformador da realidade. A internet permite essa aproximação de pessoas apesar da distância física, das dificuldades de tempo, fomentando o exercício da liberdade de expressão em um espaço novo de comunicação, nas palavras de Lévy (2002, p. 57), "[e]ste soltar a palavra, poder finalmente dizer, este mostrar e mostrar-se generalizados é uma das primeiras dimensões da revolução ciberdemocrática".

Deve-se ressaltar que o portal disponibiliza relatórios contendo os resultados dos fóruns, bate-papos e wikilégis ${ }^{8}$. Sobre os fóruns, os

\footnotetext{
8 Ambiente virtual colaborativo, no qual o cidadão pode contribuir diretamente com o processo de discussão e a redação dos projetos de lei de interesse nacional. Disponível em <http:// edemocracia.camara.gov.br/como-posso-participar\#.UwTh_2JdWSo> Acesso em 10 de out. de 2014.
} 
relatórios incluem, por exemplo, o número de tópicos, de mensagens recebidas, de membros e de visualizações. Descrevem sucintamente os assuntos debatidos e o número das respectivas postagens, fornecendo também os nomes dos membros mais ativos. Sobre os bate-papos os relatórios apresentam o número dos Projetos de Lei $(\mathrm{PL})$, o número de internautas participantes e trechos dos textos postados. Sobre o wikilégis, os relatórios apresentam o número de visualizações, se houve ou não sugestões à redação de PLs e a quantidade de comentários sobre os PLs, incluindo apresentação de resumo dos comentários.

Outro ponto de destaque no portal é a apresentação do número de usuários por unidade da Federação. Observa-se que o estado com maior número de usuários é São Paulo (SP) com número de participantes inferior a 5.500. Já o Distrito Federal (DF) e o Rio de Janeiro (RJ) estão na faixa de 2.500 usuários, seguido por Minas Gerais (MG) em torno de 2000 usuários. Os estados da Bahia (BA), Paraná (PR) e Rio Grande de Sul (RS) apresentam entre 1000 e 1.500 usuários. Os estados do Ceará (CE), Goiás (GO), Pará (PA), Paraíba (PB), Pernambuco (PE) e Santa Catarina (SC) demonstram entre 500 e 1000 usuários. Os demais estados (num total de 14) apresentam menos de 500 usuários. Desse modo, entende-se que mais de $50 \%$ do território brasileiro pouco está envolvido nas discussões ou desconhece tal instrumento. Mesmo ao se considerar que o estado de São Paulo conta com aproximadamente 5.500 usuários, isso representa $0,000125 \%$ da população do estado, levando-se em conta dados estimados para 2013 pelo IBGE $^{9}$, o qual aponta para o estado um total de 43.663.669 habitantes. Tal proporção não pode ser considerada nem representativa nem significativa em termos estatísticos. Reforçam-se aos dois fatores já mencionados anteriormente, quais sejam, educação e motivação.

O portal exige cadastro dos usuários e não deixa de ser um instrumento que pode superar algumas das dificuldades de participação política que se apresentam na atualidade, como a extensão territorial

9 Disponível em <http://www.ibge.gov.br/estadosat/perfil.php?sigla=sp> Acesso em: 20 jan. 2014 
do país, o assoberbamento com atividades de interesse individual, a falta de habilidade com o computador ou com a internet, ou a falta de interesse pelos meios tecnológicos.

A visão democrática de Nino exigia a oferta de possibilidades de participação para os indivíduos. Assim, mesmo que os números indiquem que a utilização do instrumento ainda é pequena frente ao número de indivíduos que podem dispor dele, a relevância está na oferta do mesmo. O sítio "e-democracia" entra no rol dos mecanismos à disposição para enfrentar a questão da disponibilização de mecanismos de participação para o indivíduo do século $X X I$, absorto em diferentes atividades, imerso em um grande número de informações e titular de diferentes interesses. Para esse indivíduo, o sítio disponibiliza mecanismos de rápida transferência de informação, de exposição de opiniões e de debates, mediante sua devida identificação.

\subsection{Novo sujeito: político-tecno-social}

Para Castells (2000, p. 367), as sociedades contemporâneas estão fundamentadas na mídia e as relações sociais e de poder são intermediadas pelas diversas modalidades da mídia, formando a denominada "política informacional", de modo que:

[...] a mídia eletrônica (não só o radio e a televisão, mas todas as formas de comunicação tais como o jornal e a internet) passou a se tornar o espaço privilegiado da política. Não que toda a política possa ser reduzida a imagens, sons ou manipulações simbólicas. Contudo, sem a mídia, não há meios de adquirir ou exercer poder. Portanto,todos [os partidos políticos, de ideologias distintas] acabam entrando no mesmo jogo, embora não da mesma forma ou com o mesmo propósito.

Guareschi (2007, p. 9) em sua discussão sobre mídia (o quarto poder) e política (o quinto poder), aponta que "a comunicação, hoje, constrói a realidade" e, ainda, que "a mídia não só diz o que existe e, conseqüentemente, o que não existe, por não ser veiculado, mas dá 
uma conotação valorativa à realidade existente". O autor afirma que "ao redor de $80 \%$ dos temas e assuntos que são falados no trânsito, no trabalho, em casa e nos encontros sociais são colocados em discussão pela mídia. Neste sentido, ela determina, até certo ponto, o que deve ser falado e discutido".

São muitos os exemplos de utilização das tecnologias, internet e redes sociais para informar e até formar opinião e agenda pública (agenda-setting), conforme mostrado por Cruz (2011, p. 36), o qual aponta que "no atual momento da história é a "mídia" que tem o potencial de construir socialmente uma agenda pública (agenda-setting) de assuntos, temas, personalidades e fatos sociais além da abordagem (enquadramentos) sobre cada um destes assuntos". E isso é de interesse do cidadão que "navega" na internet e "posta" nas redes sociais.

E a mídia nunca esteve tão presente quanto por meio da internet e, mais especificamente, pelas redes sociais. Tanto a internet quanto as redes sociais, somente são passíveis de existência devido ao desenvolvimento tecnológico alcançado pela sociedade contemporânea É a tecnologia que estabelece a conexão direta entre a política e as redes sociais, fazendo do cidadão o novo sujeito político-tecno-social.

Tem-se em mente que a internet não apresenta somente pontos positivos, mas não cabe a este artigo tratar dos aspectos negativos e problemas derivados do mau uso das tecnologias. Assim, positivamente, a internet proporciona a todos, de maneira igualitária, as condições necessárias para permitir, possibilitar e fomentar a expressão de pensamentos e ideias e, ao mesmo, tempo, ainda estabelecer intercâmbio de informações entre os cidadãos de uma mesma comunidade, cidade ou país.

Esses três elementos (política, tecnologia e redes sociais) perfazem um sistema contemporâneo, democrático e sem obstáculos, sejam estes geográficos, instrucionais ou de renda. Por outro lado, não se pode ignorar que os serviços de conexão não são baratos, e as operadoras disponibilizam métodos de navegação diferenciados, mesmo com o advento da neutralidade alcançado pelo Marco Civil 


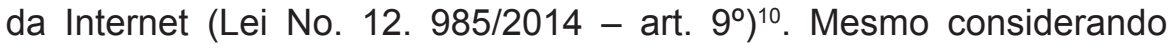
estes problemas, a ANATEL (Agência nacional de Telecomunicações) informou que "o Brasil fechou maio de 2014 com 275,45 milhões de linhas ativas na telefonia móvel"11. E, ainda, que "a banda larga móvel totalizou 123,63 milhões de acessos". Note-se que o Brasil, em 2014, alcançou a marca de 201.032.714 habitantes $^{12}$, o que estabelece uma relação de 1,37 linhas ativas de telefonia móvel por habitante.

Nesse contexto, compreende-se o surgimento deste novo sujeito, que explora a democracia de modo socialmente compartilhado por meio do uso das novas tecnologias de informação e comunicação (TIC), exercitando a democracia e participando da agenda pública. É aí que se encontram os elementos a denominá-lo: a participação política por meio da tecnologia para expressar seu papel na sociedade. Sua intervenção é possibilitada, nos dias atuais, de maneira concreta, pela tecnologia. É a tecnologia a ferramenta que possibilita uma nova aproximação do indivíduo à coletividade, um resgate de seu papel na sociedade e quiça, irá transpor obstáculos temporais e geográficos aproximando as democracias do modelo deliberativo de Nino.

\section{Conclusão}

Pergunta-se, então: surgiu um novo sujeito? Sim, um sujeito político-tecno-social, o qual possui como estrutura física a internet e estrutura lógica as redes sociais. Desse modo, as redes sociais foram descobertas como um canal pelo qual os usuários podem não somente "postar" fotos, compartilhar comentários, encontrar amigos mas se expressar em termos de política e discutir os problemas, seja do Brasil ou da sua própria rua.

\footnotetext{
10 BRASIL, Marco Civil da Internet. Disponível em: <http://www.planalto.gov.br/ccivil_03/_ato20112014/2014/lei//12965.htm> Acesso em: 20 out. 2014.

11 Disponível em: <http://www.anatel.gov.br/Portal/exibirPortalNoticias.do?acao=carregaNoticia\&co digo=34108> Acesso em : 20 out. 2014.

12 Disponível em: <http://www.brasil.gov.br/governo/2013/09/pais-supera-numero-de-200-milhoesde-habitantes-segundo-ibge> Acesso em: 20 out. 2014.
} 
Nests sentido, as redes sociais proporcionaram uma nova dimensão ao cidadão: participar da vida política do país. A tecnologia propiciou o encontro do usuário social, conhecido e presente no meio digital, com o cidadão político, aquele que almeja democracia, direitos respeitados e ampla participação.

Por certo, no momento em que esse novo sujeito político-tecnosocial for formado tão somente pelos indivíduos "nascidos" na sociedade tecnológica, mais e mais soluções serão encontradas para as dificuldades que hoje se impõem quando se pensa em advogar o uso da internet para possibilitar a participação da sociedade na tomada de decisões políticas. Assim, não se fecham os olhos para alguns óbvios problemas que se apresentarão, como garantir a identidade de quem está on-line tomando a decisão, garantir a compreensão dos temas propostos à discussão, indagar acerca dos limites mínimos de participação, acerca da possibilidade de substituição total de outras formas de participação pela digital, a própria inclusão digital, entre várias outras situações que, ao certo, irão se apresentar. Todas elas deverão ser definidas com a previsão da participação do novo sujeito.

O relatório do CETIC.br (2010, p. 75) aponta que, em termos de uso das Tecnologias de Informação e Comunicação (TIC), "o maior desafio para os governos, nos próximos anos, está em usá-las na ampliação da prática democrática". E a prática de participação do cidadão somente poderá ocorrer se este tiver "alternativas de fazê-lo em diferentes canais, reduzindo restrições de mobilidade, de acesso, de exposição". E, pondera que "a apropriação das ferramentas tecnológicas pelos grupos já melhor preparados para exercerem o poder leva a uma desigualdade nos resultados alcançados".

Assim, o que se quer defender é que os pontos positivos da democracia ateniense foram abandonados pela necessidade do desenvolvimento do Estado-Nação e pela complexidade crescente das sociedades. Todavia, não se nega que o ideal da participação, apesar de utópico, seria de concretização bem-vinda. O que se fez foi aliar o desenvolvimento tecnológico, em especial na área da internet, para 
lançar luzes sobre uma nova possibilidade de participação democrática do cidadão, o novo sujeito político-tecno-social.

\section{Referências}

CASTELLS, Manuel. A sociedade em rede. 2. ed. São Paulo: Paz e Terra, 1999.

. O poder da identidade. Tradução de Klauss Brandini Gerhardt. 2. ed. São Paulo: Paz e Terra, 2000.

A galáxia internet: reflexões sobre internet, negócios e sociedade. Tradução de Rita Espanha. 2. ed. Lisboa: Fundação Calouste Gulbenkian, 2007.

CENTRO DE ESTUDOS SOBRE AS TECNOLOGIAS DAINFORMAÇÃO E DA COMUNICAÇÃO. Pesquisa sobre o uso das tecnologias da informação e da comunicação no Brasil: 2005-2009. São Paulo: Comitê Gestor da Internet no Brasil, 2010.

. Pesquisa sobre o uso das tecnologias de informação e comunicação no Brasil: TIC Domicílios e TIC Empresas 2011. São Paulo : Comitê Gestor da Internet no Brasil, 2012.

CRUZ, Marcio. A mídia e os formadores de opinião no processo democrático. Ponto-e-vírgula, São Paulo, v. 9, p. 35-51, 2011.

FREITAS, Cinthia Obladen de Almendra. Redes sociais: sociedade tecnológica e inclusão digital. In: WACHOWICZ, Marcos (Org.). Direito da sociedade da informação \& propriedade intelectual. 1. ed. Curitiba: Juruá, 2012, v. 1, p. 43-65.

- Sociedade da informação e darknets. In: WACHOWICZ, Marcos; PRONER, Carol (Org.). Inclusão tecnológica e direito a cultura: movimentos rumo à sociedade democrática do conhecimento. 1. ed. Florianópolis: Fundação Boiteux, 2012. v. 1, p. 66-87.

GUARESCHI, Pedrinho A. Mídia e democracia: o quarto versus o quinto poder. Revista DEBATES, Porto Alegre, v. 1, n. 1, jul./dez. 2007, p. 6-25. 
GREENFIELD, Adam. Everyware: the dawning age of ubiquitous computing. AIGA: New Riders, 2006.

HABERMAS, Jurgen. Direito e democracia: entre facticidade e validade. Rio de Janeiro: Tempo Brasileiro, 1997.

HORRIGAN, Jonh. Themobile difference. Pew Internet, 2009. Disponível em: <http://www.pewinternet.org/files/old-media/Files/ Reports/2009/The_Mobile_Difference.pdf>. Acesso em 20 out. 2014.

LÉVY, Pierre. Ciberdemocracia. Tradução de Alexandre Emílio. Editions Odile Jacob: Paris, 2002.

MENDES, Conrado Hübner. Is it all about the last word? deliberative separation of powers I. Disponível em: <http://www.researchgate. net/ publication/228127867_Is_it_All_About_the_Last_Word_Deliberative_ Separation_of_Powers_1>.Acesso em: 20 out. 2014.

MORAES, Érika. Autoria e democracia na comunicação em midiassociais. Signo, Santa Cruz do Sul, v. 36, n. 61, p. 264-278, jul./ dez. 2011. Disponível em <http://online.unisc.br/seer/index.php/signo/ article/view/2114/1781> Acesso em: 20 out. 2014.

MARTELETO, Regina Maria. Análise de redes sociais: aplicação nos estudos de transferência da informação. Ciência da Informação, Brasília, v. 30, n. 1, p. 71-81, jan./abr. 2001.

MOUTINHO, Ana Maria. Inteligência ambiente: contributo para a conceptualização de parede inteligente. 2010. Dissertação (Mestrado) Universidade de Lisboa, Lisboa, 2010. Disponível em <http://repositorio. ul.pt/bitstream/10451/7277/2/ULFBA_tes\%20392.pdf> Acesso em: 20 out. 2014.

NINO, Carlos Santiago. La constitución de la democraciadeliberativa. Barcelona: Gedisa, 1999.

. Los escritos de Carlos S. Nino: derecho, moral y politica. Buenos Aires: Gedisa, 2007.

PRENSKY, Marc. Digital natives, digital immigrants. On the Horizon, Maryland, v. 9, n. 5, p. 1-6. 2001. 
PRZEWORSKI, Adam. Sustainable democracy. Cambridge: Cambridge University Press, 1995.

RAWLS, John. Uma teoria da justiça. 3. ed.; São Paulo: Martins Fontes, 2008.

SILVA, Daniel Martins de Lima. Globalização, comunicação e democracia: dos conglomerados ao ativismo de mídia. LOGOS 28: Globalização e comunicação internacional, Rio de Janeiro, ano 15, p. 124-131, 2008. Disponível em <http://www.logos.uerj.br/PDFS/28/09 DanielMartinsresenha.pdf>. Acesso em: 20 out. 2014.

VILANI, Maria Cristina Seixas. Origens medievais da democracia moderna. Belo Horizonte: Inédita, 2000.

WEISER, Mark. Some computer science issues in ubiquitous computing. Communications of the ACM. Disponível em<http://www. ubiq.com/hypertext/weiser/UbiCACM.html>. Acesso em: 20 out. 2014.

Recebido em: 28/02/2014

Aprovado em: 06/06/2014 